\title{
On the Importance of Strength Training in Occupational Etiquette Shape-building
}

\author{
Yanghui Xu' ${ }^{1}$ Meng Gong' ${ }^{2}$ Yu Yu ${ }^{1}$ \\ ${ }^{1}$ Chongqing Real Estate College, Chongqing, China \\ ${ }^{2}$ Chongqing Electric Power College, Chongqing, China
}

Keywords: shape building; strength training; posture

\begin{abstract}
Strength is foundation of pretty figures, and the basic ability which can enhance human's expressive force. This paper explores the importance of strength training in vocational etiquette body training, and provides the method of training "artists" with pretty figures.
\end{abstract}

\section{Introduction}

Strength is the source of body beauty, and the basic ability which can enhance human's expressive force. In postures related to occupational etiquette, the standing posture needs support force, walking and picking up things need stability, while holding things needs controlling force. Strength is the cornerstone of human; strength training is the basis of occupational etiquette body shaping.

\section{Overview of Beauty}

\subsection{The classification of beauty.}

Beauty includes external beauty and inner beauty, in which external beauty includes natural beauty and decorative beauty. The face, appearance, skin color and eye expression form the natural beauty of a person; while decorative beauty is consisted of makeup, clothing and accessories.

\subsection{Overview of body shaping.}

Body building belongs to natural beauty, which includes the innate body posture and body posture after training. Vocational etiquette requires pretty figures which can help people to build personal images and enhance professionalism.

The beauty of form includes the beauty of bodily form and the beauty of posture.

Bodily form. Beautiful bodily form includes the balance of height and weight, the coordination of bones and muscles, the smooth lines of the waist and abdomen and the strong body. Muscles should be long, elastic and with soft texture. Beautiful bodily form requires good endurance as well as controlling and explosive forces.

Unbeautiful bodily forms include uncoordinated proportion of skeleton and muscles, as well as abnormal physiological curve of cervical vertebrae, lumbar vertebrae and caudal vertebrae.

Reasons of unbeautiful bodily forms:

(1) genetic factors.

(2) overweight or abnormal physiological curve caused by long-term incorrect physical postures

(3) lack of effective exercises lead to fat or thin bodies

Posture. Beautiful posture means, when a person is walking, sitting, squatting, turning or guiding others, his or her posture and expression are beautiful and elegant. The postures of some people are full of energy, while others are lazy and sluggish.

Unattractive postures include valgus deformity, humpback, round shoulders, hyperextension or over flexion of cervical spine, high and low shoulders and so on. The reasons are complicated. Some basic causes are listed as following.

The causes of unbeautiful postures. Valgus deformity: possible reasons include congenital 
mal-development, standing during infancy, long time walking and calcium deficiency. People with valgus deformity cannot put their knees together when standing, due to the balance between the internal and external muscles of their legs and the contraction force of ligaments. They suffer from osteoarthritis caused by knee joint varus, which can lead to cartilage surface wear in knee joint and tibial plateau collapse. Their joints usually pain, which even affects their daily activities.

Humpback, hyperextension or hyper flexion of cervical vertebra: for learners with incorrect posture and mobile phone addicted group, long-term maintenance of a fixed movement causes abnormal stiffness in back muscles and weak muscle strength. The back ligament pulled by anterior ligament leads to neck extension and back protruding, which directly influence the body heights and postures of learners. The back muscles are very important in maintaining the stability of spine and keeping correct posture, [1] and directly affecting the overall image of people.

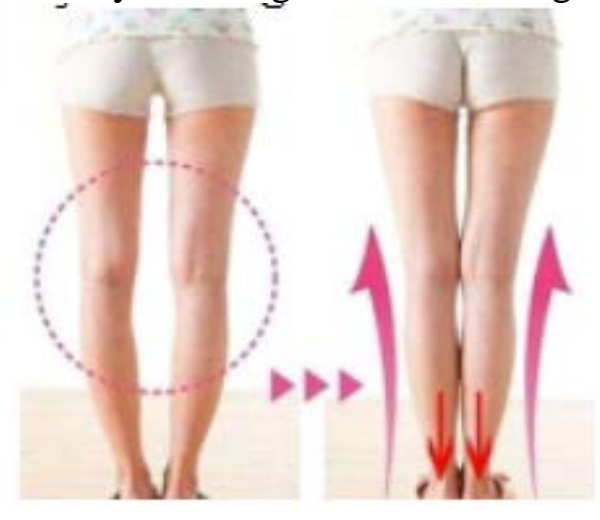

Figure 1. Valgus deformity and normal leg

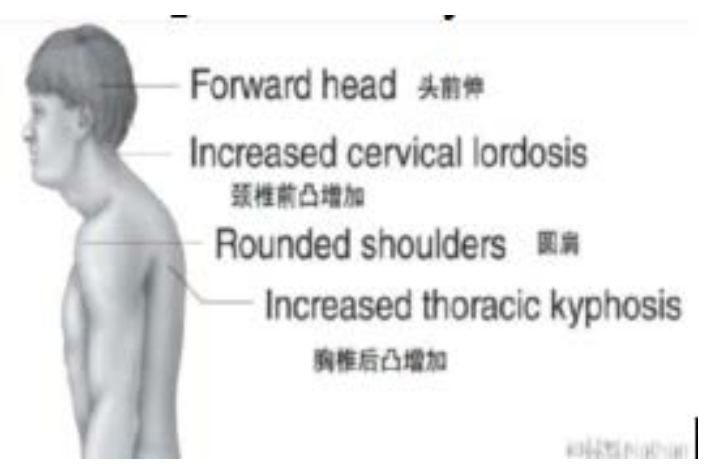

Figure 2. Humpback, cervical spine hyperextension

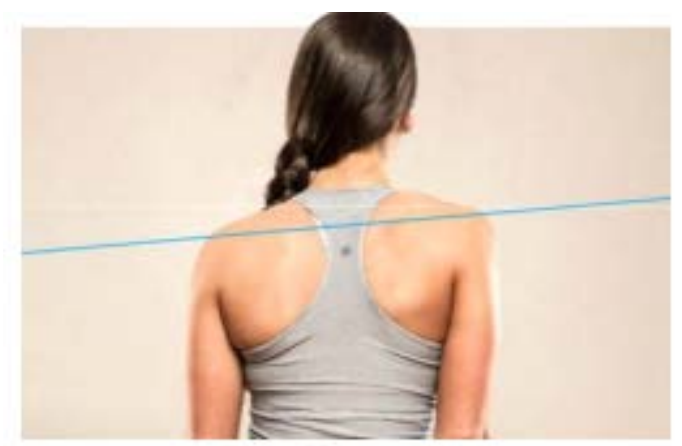

Figure 3. High and low shoulders

(Source of above pictures: Baidu pictures)

High and low shoulders: due to the uneven development of muscles on both sides, scoliosis, uneven leg length or incorrect posture when carrying hold things

\section{The Influence of Strength Training on Body-shaping}

Strength training in vocational etiquette can effectively change relax, sturdy or skinny muscles to 
become strong and lean muscles. Trainees can have smooth body lines, long necks, arms and legs, as well as upright upper bodies and slim waists. Strength has many functions; the power of stability and controlling forces are two functions related to etiquette.

The power of stability refers to the strength needed in body posture maintaining; through the static contraction of muscles, people can keep the stable of body and gravity centers. [2]

For example, in basic postures of human body, the standing posture requires the stability of spine. The spine runs through the middle of back, with cervical spine at the upper part and tail vertebra at the lower end. Once the spine is weak or damaged, the body will be adversely affected; scoliosis or humpback may appear. Another example is the guiding position in reception etiquette, which can be divided into horizontal posture (single arm, double arm), oblique pendulum, curved arm posture and straight closed posture. All these postures need to be continued for a period of time. In that process, the stability force plays an important role. Taking the "please" posture as an example, it requires relaxed shoulders with contracted arm muscles and folded elbow joints; the small arms move from inside to the front of body; five fingers naturally close together; the palm should keep flat while the strength is required to reach the point of fingers. This posture starts at about 1 to 2 meters away before the guest arrives until the guest leaves. The stability of muscles can bring elegance, implicative and courteous feelings.

The controlling force is used to complete actions through the contraction of muscles. [3] In the service industry, trays are used in awards ceremony, venue, catering industry and so on. Holding the tray requires the forearm forward, the palm upwards and four fingers close together. The thumb is responsible for controlling the tray and improving stability. In this process, the stability of muscles is especially important. Of course, the functions of power are complementary. In movements like bows, the joint effect of muscle stability and controlling force is required.

\section{Methods of Strength Training}

\subsection{Basic postures on strength training.}

Standing posture. Standing posture at the original station. When standing, keep the mandible parallel to the ground, and hold a yoga brick or a book on the head. The aim is to raise the support strength of muscles in neck and back. At the same time, the trainees need to tighten the ischium and fill the groin, in order to improve the contraction force of gluteus maximus muscle. The posture can effectively link the upper and lower half of the body and avoid lumbar disc herniation caused by "raised buttock". The training of knee upward pulling can tighten front muscles of the thigh and achieve a firm feeling.

Carrying a cross on the back. This posture is mainly aimed to fix hump body. When standing, a wooden cross is fixed behind the trainee; the trainees need to actively extend their spines upward and exercise their latissimus dors to improve the controlling abilities of muscle.

Walking posture. hen walking, hold a dumbbell in hand can improve the muscle of arms. When the foot is lifted, the heel should touch the ground first, then to the middle and front of the foot.

With a Yoga brick or book above the head, ladies are required to walk exactly along a line step by step. Walking slowly and steadily, touching the inside part of knees when changing legs, and pulling the front side of thighs, can effectively avoid the "climbing step". When men walks the line, the width of line should be 4 to $10 \mathrm{~cm}$. Wide lines should be used first. With the progressive training effects, the width should be gradually reduced, so as to help men consciously correct their actions.

Holding things. Movements like body forward bending with dumbbell, pushing up and clapping hands when pushing up can train upper limbs, improve stamina and endurance.

\subsection{Forms of strength training.}

Static training. Static training is mainly aimed to improve the endurance, stability and balance of muscles in certain parts by controlling certain actions. Steady breathes are required during all movements. For professional people, to remain calm and cope with sudden situations in the service process is required by vocational etiquette. 
Transformation training. Transformation training means training muscle strength and speed through the transformation of movements.

\subsection{Strength training methods.}

Strength training methods include decomposition training method, complete training method, repetitive training method, interval training method, continuous training method, transformation training method, circular training method and competition training method.

\subsection{Targeted strength training.}

Core parts. The abdomen. The abdomen connects the waist and the crotch; it equals to the bridge between the two parts. If the abdominal strength is insufficient, the upper body and the lower body will be disjointed and the strength cannot "flow". The strength of the abdomen is divided into two modules, the large abdominal muscles (close to the stomach, a bit above the abdomen) and the small abdominal muscles (the position below the navel). [4] With back on floor, lifting upper body or legs fast can train the large abdominal muscles. Small abdominal muscles can be trained through supine pedal bicycle and five points attacking. Feet must leave the ground when practicing, but the closer with ground will be the better. When training the back muscle, trainers can use the supine position, and relax the rest of body, especially muscles in shoulder and neck, and try to focus on the back and back waist. With the improvement of abilities, trainers can move their focus to the anterior parts of arms and thighs to improve training effects. The rectus abdominis and oblique can be effectively exercised through sit-ups with legs bent.

The waist. The middle part of our body is formed with waist and abdomen; it is the core part of our body. The tension and flavor of our body language greatly depends on the flexibility of the waist. The waist can be trained through pressing and dropping.

Other parts. Sole. The foot of human body is equivalent to the foundation of building. Only if the foundation is stable, can we have stable bodies. Thus, the training of sole pressure cannot be ignored. Training methods include lifting the heel in place, raising the heel at the edge of platform, and lifting the heel when standing.

When standing, lift the heel up and pay attention to the control of body. Stretching the body upward as a whole; stretching forward is not correct, since the strength will be scattered. The power is pushed to the front of big toe. This training method helps to improve the stress of feet. When the strength of floor is great enough, the upper extremity can be more extensible like big trees with root underground. Standing at the edge of platform edge will strengthen the elasticity of Achilles tendon, and enhance the compactness degree of gastrocnemius muscle at the same time.

Legs. The supporting strength of legs is important in standing and walking postures. Training methods include pressing legs, raising legs and stretching the Achilles tendon.

As shown in above table, through a series of targeted strength training, it is possible for students to build balanced bodies with beautiful and strong muscles, so as to improve the coordination ability of their limbs, and make their body movements full of beauty. After training, trainees can be graceful in every movement. 
Table 1 Form and Methods of Strength Training

\begin{tabular}{|c|c|c|c|}
\hline $\begin{array}{l}\text { ways of } \\
\text { training }\end{array}$ & $\begin{array}{l}\text { Training } \\
\text { forms }\end{array}$ & Training method & muscle \\
\hline \multirow[t]{5}{*}{ Static training } & \multirow[t]{5}{*}{ Unarmed } & $\begin{array}{l}\text { Standing against the } \\
\text { wall }\end{array}$ & $\begin{array}{l}\text { gluteus maximus, latissimus } \\
\text { dorsi }\end{array}$ \\
\hline & & Standing with barre & $\begin{array}{l}\text { gluteus maximus, latissimus } \\
\text { dorsi }\end{array}$ \\
\hline & & front layout & latissimus dorsi \\
\hline & & Sloping plate & $\begin{array}{l}\text { Ectopectoralis, Deltoid muscle, } \\
\text { triceps muscle of arm }\end{array}$ \\
\hline & & curl-up & abdominal muscle \\
\hline \multirow{13}{*}{$\begin{array}{l}\text { Transformation } \\
\text { training }\end{array}$} & \multirow[t]{2}{*}{ barre } & toe-raise & gastrocnemius muscle, soleus \\
\hline & & $\begin{array}{l}\text { toe-raise up and } \\
\text { down }\end{array}$ & gastrocnemius muscle, soleus \\
\hline & \multirow[t]{5}{*}{ dumbbell } & shrug & musculi patientiae, supraspinatus \\
\hline & & Front raise & $\begin{array}{l}\text { musculi patientiae, Deltoid } \\
\text { muscle, supraspinatus }\end{array}$ \\
\hline & & side raise & $\begin{array}{l}\text { Deltoid muscle, musculi } \\
\text { patientiae }\end{array}$ \\
\hline & & upthrow & $\begin{array}{l}\text { rectus abdominis, musculus } \\
\text { obliquus externus abdominis }\end{array}$ \\
\hline & & body ante flexion & $\begin{array}{l}\text { iliopsoas, rectus femoris, } \\
\text { sartorius }\end{array}$ \\
\hline & \multirow[t]{6}{*}{ unarmed } & $\begin{array}{l}\text { deep knee bend } \\
\text { board }\end{array}$ & $\begin{array}{l}\text { rectus abdominis, musculus } \\
\text { obliquus externus abdominis }\end{array}$ \\
\hline & & $\begin{array}{l}\text { Planche clap push } \\
\text { ups }\end{array}$ & $\begin{array}{l}\text { Ectopectoralis, bicipital muscle } \\
\text { of arm, brachioradialis }\end{array}$ \\
\hline & & sit-ups & Large abdominal muscle \\
\hline & & $\begin{array}{l}\text { Lie down and lift } \\
\text { legs }\end{array}$ & Large abdominal muscle \\
\hline & & inverted bicycle ride & $\begin{array}{l}\text { Small abdominal muscle, } \\
\text { quadriceps femoris }\end{array}$ \\
\hline & & Five points attack & Small abdominal muscle \\
\hline
\end{tabular}

\section{Conclusion}

Power plays an essential role in the balance and stability of human bodies. Through strength training, we can build beautiful, stable and enduring muscles. Therefore, in order to build beautiful bodies and cultivate graceful manners in vocational etiquette, strength training must be carried out.

\section{References}

[1] [3] W.F. Jiang, Z.Q. Jin, P.J. Zhao, et al., Functional training in humpback correction among obese male college students, J. Physical Education. 12 (2014).

[2] O. Yang, Principles and Methods of Strength Training in Dance, Shanghai Music Publishing House, Shanghai, 2012.

[4] P.P. Tian, Dance and Body training, People’s Music Publishing House, Beijing, 2014. 